\title{
PROBLEMATIKA MUALLAF DALAM MELAKSANAKAN AJARAN AGAMA ISLAM DI DESA TUMBANG RUNEN KECAMATAN KAMIPANG KABUPATEN KATINGAN
}

\section{Muallaf Problematic in Implementing Islamic Teaching in The Tumbang Runen Village Kamipang District Katingan Regency}

\author{
*Supriadi \\ Lecturer in Islamic Education, Universitas Muhammadiyah Palangkaraya, RTA Milono St. Km. I,5, Palangka Raya, Indonesia \\ *e-mail : adianstercool@yahoo.com
}

\begin{abstract}
ABSTRAK
Muallaf merupakan orang yang baru masuk agama Islam dan imannya masih sangat lemah serta memerlukan pemantapan diri dalam agama barunya itu. Maka dari itu perlunya pembinaan untuk para muallaf, agar kedepanya tetap lebih baik dan tetap kokoh aqidahnya dalam ajaran Islam. Rumusan masalah dalam penelitian ini adalah bagaiamana problematika yang dihadapi keluarga muallaf dalam melaksanakan ajaran Islam serta bagaimana cara mengatasi problematika yang dihadapi keluarga muallaf dalam melaksanakan ajaran Islam di desa Tumbang Runen Kecamatan Kamipang Kabupaten Katingan. Penelitian ini bertujuan untuk mengetahui bagaiamana problematika yang dihadapi keluarga muallaf dalam melaksanakan ajaran Islam serta bagaimana cara mengatasi problematika yang dihadapi keluarga muallaf dalam melaksanakan ajaran Islam di desa Tumbang Runen Kecamatan Kamipang Kabupaten Katingan. Penelitian ini adalah penelitian kualitatif, yaitu data yang terkumpul dalam bentuk kata-kata yang menggunakan beberapa teknik pengumpulan data yang meliputi teknik wawancara, observasi dan dokumentasi. Subjek dalam penelitian ini adalah 5 orang muallaf. Hasil penelitian menunjukan bahwa problematika muallaf dalam melaksanakan ajaran islam di desa tumbang runen kecamatan kamipang kabupaten katingan dari data dikumpulkan keluarga muallaf menghadapi problematika dalam melaksanakan ajaran Islam terutama rukun Islam yang menjadi masalah dari keluarga muallaf terutama rasa malas dalam melaksanakan shalat dan puasa ramadhan, kurangnya kesadaran dari hati muallaf, kebimbangan dalam melaksanakan kewajiban, meluangkan waktu untuk melaksanakan kewajiban dan mencari-cari kecocokan dalam mempelajari ajaran Islam.
\end{abstract}

Kata kunci: Problematika, Muallaf, Ajaran Islam

\begin{abstract}
Muallaf is a new convert to Islam and his faith is still very weak and requires consolidation in his new religion. Therefore the need for guidance for the converts, so that kedepanya still better and remain firm aqidahnya in Islamic teachings. The formulation of the problem in this research is how problematic faced by the muallaf family in implementing Islamic teachings and how to overcome the problems faced by the muallaf family in implementing the Islamic teachings in the village of Tumbang Runen Kamipang District Katingan Regency. This study aims to determine how the problems faced by the mufallaf family in implementing Islamic teachings and how to overcome the problems faced by the family of muallaf in implementing Islamic teachings in the village of Tumbang Runen Kamipang district Katingan regency. This research is a qualitative research, the data collected in the form of words that use some data collection techniques that include interview techniques, observation and documentation. Subjects in this study are 5 people convert. The results showed that the problem of muallaf in implementing the teachings of Islam in the village tumbang runen kamipang district katingan district of the data collected muallaf families facing problematics in implementing Islamic teachings, especially the pillars of Islam which is a problem of the family of muallaf especially the sense of lazy in performing prayers and fasting Ramadan, lack of awareness from the hearts of the converts, the hesitation in carrying out the obligations, taking the time to carry out the obligations and looking for compatibility in studying the teachings of Islam.
\end{abstract}

Keywords: Problematic, Muallaf, Islamic Teaching

\section{PENDAHULUAN}

Seorang muallaf setelah memeluk agama baru yaitu agama Islam, mereka harus menjalankan syari'at ajaran-ajaran agama Islam secara baik. Mulai dari menjalankan shalat wajib lima waktu, puasa ramadhan, zakat fithrah, haji, mempercayai rukun Islam, melakukan muamalah sesuai dengan syari'at Islam dan ajaran-ajaran yang lain sesuai dengan ketentuan syari'at. Bagi muallaf semua hal ini adalah hal yang masih terlalu asing untuk mereka jalani dalam kehidupan sehari-hari.
Setiap muallaf mempunyai masalah yang berbeda-beda, dicontohkan dari ajaran-ajaran agama Islam yang paling dasar, seperti ada yang hanya mengalami kesulitan dalam melaksanakan shalat lima waktu, masalah melaksanakan puasa ramadhan, masalah melaksanakan zakat, dan masalah melaksanakan mu'amalah di kehidupan ini. Ada yang tahu sedikit tentang Islam karena di lingkungan sekitar mayoritas beragama Islam, bahkan ada yang sama sekali belum mengetahui tentang ajaran agama Islam.

Muallaf yang merupakan orang yang baru masuk agama Islam dan imannya masih sangat lemah serta memerlukan 
pemantapan diri dalam agama barunya itu. Jadi muallaf itu bukan hanya orang yang baru masuk Islam saja, tetapi mempunyai arti yang sangat luas.

Desa Tumbang Runen Kecamatan Kamipang Kabupaten Katingan, ada beberapa keluarga muallaf. Penduduk di desa Tumbang Runen mayoritas agamanya 100\% beragama Islam, di desa itu nilai-nilai agamanya cukup baik. Di setiap hari anak-anak setelah pulang sekolah melanjutkan kegiatan dengan belajar mengaji, begitu juga untuk orang yang dewasa mereka melaksanakan yasinan setiap hari jum'at.

Dalam kasus para muallaf ini, mereka akan selalu benar dalam menjalankan perintah Allah dan mendalami ajaran Islam. Sedangkan para muallaf yang Islamnya dikarenakan oleh keturunnanya biasanya hanya sekedar mengikuti pasangannya. Maka dari itu perlunya pembinaan untuk para muallaf, agar kedepanya tetap lebih baik dan tetap kokoh aqidahnya dalam ajaran Islam. Dalam mendidik agama pada seorang muallaf diperlukan pendekatan-pendekatan tertentu, diantaranya melalui pendekatan melalui pengajaran kepada mereka.

Berdasarkan hasil Observasi awal yang diamati oleh penulis di Desa Tumbang Runen Kecamatan Kamipang Kabupaten Katingan, ada lima keluarga muallaf yang telah diteliti tentang keagamaannya. Di desa Tumbang Runen itu muallaf hampir belum bisa membaca huruf hijaiyyah, terkadang bacaan sholat pun masih ada yang belum dihafalkan. Mereka hanya bisa melakukan gerakkan sholat. Sehingga muallaf di Desa Tumbang Runen belum bisa mencapai seperti apa yang di inginkan. Untuk penyampaian yang seharusnya dilakukan kepada keluarga muallaf melalui pendekatan berbicara tentang Islam, mengajak keluarga muallaf untuk belajar mengenal/membaca huruf hijaiyyah, dan mengajarkan tata cara wudhu, sholat serta bacaannya.

Observasi menunjukkan permasalahan dalam mengamalkan rukun Islam yang dihadapi para muallaf adalah melaksanakan shalat fardlu dan puasa di bulan ramadhan.

Hal yang menjadi latar belakang keluarga muallaf adalah problematika yang dihadapi keluarga muallaf dalam melaksanakan ajaran Islam, terutama rukun Islam dan solusi untuk keluarga muallaf agar dapat melaksanakan ajaran Islam dengan baik.

Dalam Kamus Besar Bahasa Indonesia problematika berasal dari bahasa inggris yaitu "problematic" yang artinya persoalan atau masalah. Sedangkan menurut bahasa Indonesia, problema berarti hal yang belum dapat dipecahkan yang menimbulkan permasalahan.

Problema adalah berbagai persoalan-persoalan sulit yang dihadapi dalan proses pemberdayaan, baik yang datang dari individu Tuan Guru (Faktor eksternal) maupun dalam upaya pemberdayaan masyarakat Islami secara langsung dalam masyarakat. Problematika dakwah itu terbagi kedalam dua faktor intern dan faktor ekstern :

\section{Faktor Intern}

Problematika datangnya dari dalam atau faktor intern cukup banyak diantaranya :

a. Pengaruh adat istiadat yang sudah mendarah daging.

b. Tingkat pengetahuannya tidak sama dalam suatu forum pengajian atau majelis taklim

2. Faktor ekstern

Yang menjadi kendala atau dakwah ini bukan saja faktor intern, tapi juga faktor ekstern. Hal ini mencakup diantaranya :

a. Pengaruh budaya asing baik itu melalui film, video dan banyak hal lainnya.

b. Pengaruh ideologi yang mendiskreditkan Islam.

c. Aparat atau penegak hukum yang sudah terlanjur alergi terhadap Islam.

d. Peraturan dan undang-undang yang kurang mendukung terhadap kegiatan dakwah.

Di dalam strukutur tiap-tiap agama biasanya terdapat dua ajaran yang terpenting, pertama adalah ajaran yang memberi ketentuan tentang soal kepercayaan dan kedua ajaran yang memberikan ketentuan tentang apa yang harus dilakukan pemeluk agama itu, sebagai tanda bukti bahwa seseorang percaya terhadap apa yang diajarkan oleh ajaran yang pertama itu.

Demikian pula di dalam struktur agama Islam terdapat dua ajaran yang terpenting, yang dianggap sebagai soko guru agama Islam.

Soebardi dan Harsojo, menjelaskan pilar atau macam-macm rukun Islam dalam buku yang berjudul "Pengantar Sejarah dan Ajaran Islam”, yaitu sebagai berikut:

I. Syahadah (syahadatain)

Rukun Islam yang pertama yaitu syahaadah, berbunyi: "Asyhadu allaa ilaaha illallaah, wa asyhadu anna Muhammadar Rasuulullah, yang berarti: saya bersaksi bahwa tidak ada Tuhan melainkan Allah dan saya bersaksi bahwa Muhammad utusan Allah."

2. Salat

Salat adalah wajib bagi tiap orang muslim, baik laki-laki maupun perempuan yang telah sampai umur dan yang telah dapat membedakan baik dan buruk. Sebaliknya tidak wajib bagi mereka yang kurang umur, meskipun 
menurut hukum Islam anak yang berumur 7 tahun sudah dianjurkan salat.

\section{Zakat}

Zakat menjadi rukun Islam yang ketiga dalam rukun Islam. Pengertian zakat menurut istilah agama Islam adalah kadar harta yang tertentu diberikan kepada yang berhak menerimanya dengan beberapa syarat.

4. Saum (puasa)

Saum (puasa) adalah rukun Islam yang keempat mengartikan puasa sebagai berikut, shaum menurut bahasa Arab menahan dari segala sesuatu seperti menahan tidur, menahan berbicara, menahan makan, dan sebagainya. Sedangkan menurut istilah agama Islam yaitu menahan diri dari pada sesuatu yang membukakan, satu hari lamanya mulai terbit fajar sampai terbenam matahari dengan niat dan beberapa syarat.

5. Hajj (naik haji) bagi mereka yang sanggup menjalankannya

Haji merupakan rukun Islam yang kelima. Yang dimaksud dengan haji ialah pergi ke Mekah sengaja hendak melakukan upacara haji sebagaimana yang diperintahkan oleh Allah. Hajj mula-mula berarti pergi ke sesuatu benda untuk mengunjunginya. Dan dalam terminologi hukum syari"at berarti pergi ke baitullah (rumah Allah) guna melakukan upacara agama yang tertentu.

Dari tutunan dan ajaran agama islam merupakan kepentingan mutlak setiap orang dan setiap orang beragama terlibat dengan agama yang dipeluknya, maka tidaklah mudah membuat sebuah definisi yang mencakup semua agama. Kesulitannya adalah karena setiap orang beragama cendrung memahami agama menurut ajaran agamanya sendiri. Hal ini ditambah lagi dengan fakta bahwa dalam kenyataan agama didunia ini amat beragam. Namun, karena ada segi-segi agama yang sama, suatu rumusan umum (sebagai define kerja) mungkin dapat dikemukakan

\section{METODE PENELITIAN}

Dalam mengungkapkan permasalahan yang ada, maka peneliti menggunakan pendekatan kualitatif. Adapun penulis menganalisis data adalah metode deskriptif, yaitu metode yang meneliti suatu sekelompok manusia, objek, kondisi, sistem pemikiran ataupun kelas pada masa sekarang.

Metode ini memungkinkan untuk menggambarkan secara sistematis, aktual dan akurat mengenai problematika keluarga muallaf dalam melaksanakan ajaran Islam. Sehingga dapat melaksanakan pemudahan informasi keislaman terhadap keluarga muallaf.

\section{HASIL DAN PEMBAHASAN}

Deskripsi Problematika Muallaf Dalam Melaksanakan Ajaran Islam Di Desa Tumbang Runen Kecamatan Kamipang Kabupaten Katingan merupakan Problematika yang dialami keluarga muallaf seperti melaksanakan ajaran agama Islam seperti mengamalkan rukun Islam dan solusi untuk memecahkan problematika yang dialami oleh muallaf.

Hasil penelitian dari problematika muallaf dalam melaksanakan ajaran islam di desa tumbang runen kecamatan kamipang kabupaten katingan argument dari tetangga SM bahwa dia memang sering malas dalam melaksanakan ibadah. Padahal mertuanya sering melaksanakan sholat dan juga mengikuti yasinan pada hari jum'at.

Menurut argument dari keluarga dari suami NV, bahwa NV tidak mau tau tentang melaksanakan ibadah, padahal banyak teman-temannya mengajak NV untuk melaksankan sholat di masjid. NV sering berkata kepada temannya :

"Ketun ih helu kan masjid tau ku manggawi melai huma ih."

Terjemahan bahasa Dayak ke bahasa Indonesia :

"Kalian aja ke masjidnya, saya bisa melaksanakannya dirumah"

Padahal di rumah NV tidak mengerjakannya sama sekali, malah di ajak kakak dan mertuanya shalat berjamaah di rumah, dia berkata masih belum siap untuk melaksanakannya.

Dari argument tentang muallaf SR, bahwa memang SR lebih mengutamakan pekerjaan daripada kewajiban. Disaat bulan ramadhan SR jarang melaksanakan puasa ramadhan. Padahal di rumahnya dari yang berumur 4-5 tahun sudah dilatih untuk menjalankan puasa ramadhan.

Selanjutnya argument dari tetangga SS, bahwa SS memang suka memilih orang tempat belajar, padahal di desa tumbang runen ada guru yang khusus mengajarkan tentang agama Islam. Terutama untuk belajar hurup hijayyah dan al-qur'an. SS juga suka memilih teman untuk bergaul, jika tidak ada teman yang cocok tempat bergaul maka SS lebih memilih berdiam diri di rumah.

Kemudian argument terakhir dari keluarga muallaf yang berinisial $A A$, bahwa $A A$ terlalu sibuk dengan pekerjaan sehingga melalaikan kewajiban. Padahal mertua dari AA tersebut adalah orang yang bisa disebut tokoh agama di desa Tumbang Runen. Namun AA tidak dapat meluangkan waktunya untuk belajar tentang ajaran Islam, terutama ajaran Islam. 


\section{KESIMPULAN}

Dari hasil penelitian disimpulkan bahwa keluarga muallaf menghadapi problematika dalam melaksanakan ajaran Islam terutama "rukun Islam". Namun yang menjadi masalah dari keluarga muallaf adalah rasa malas dalam melaksanakan shalat dan puasa ramadhan, kurangnya kesadaran dari hati muallaf, kebimbangan dalam melaksanakan kewajiban, meluangkan waktu untuk melaksanakan kewajiban dan mencari-cari kecocokan dalam mempelajari ajaran Islam. Untuk mengatasi problematika yang dihadapi keluarga muallaf dalam melaksanakan ajaran Islam, para muallaf seharusnya mempunyai kemauan untuk mengatasi masalahnya. Mereka mengatasinya dengan cara belajar ilmu agama Islam kepada sesama muslim atau ustadz, belajar melalui buku-buku tentang syari"at Islam, bergaul dengan sesama orang Islam. mengikuti pengajian rutin, dan lebih utama kesadaran dari hatinya karena kewajiban mereka setelah memeluk agama Islam adalah mempelajari ajaran Islam, terutama "Rukun Islam" yang terdiri dari Syahadat, Shalat, Puasa, Zakat dan Haji bagi yang mampu untuk menunaikan ibadah haji.

\section{DAFTAR PUSTAKA}

Abduh, Syaikh Muhammad, Islam, Ilmu Pengetahuan dan Masyarakat Madani. Terj. Haris Fadillah dan Muhammad Abqory. Jakarta: PT RajaGrafindo Persada, 2005.

Buseri, Kamrani, Pendidikan Keluarga Dalam Islam. Yogyakarta : Bina Usaha, 1990.

Daradjat, Zakiah, Ilmu Jiwa Agama. Jakarta: Bulan Bintang, 1991.

Daud, M. Ali, Kerangka Dasar Agama dan Ajaran Islam. Jakarta : Raja Grafindo Persada, 2004.

Husiani Usman, Metodologi penelitian Sosial. Bumi Aksara, Jakarta, 1996.

Kasiram, Kamus Besar Bahasa Indonesia. Jakarta: Balai Pustaka, 2007.

Mukti, H.A. Ali : Memahami Aspek Ajaran Islam , Bandung, Mizan, 1990.

Moleong, Lexy J. Metodologi Penelitian Kualitatif. Bandung: PT Remaja Rosdakarya, 20II.

Mathew B. Miles dan A. Michael Huberman, Analisis data Kualitatif, Tjetjep Rohenal Rohidi, Jakarta: UI press, 1992.
Prawira, R. Anwar, Petunjuk Praktis Bagi Calon Pemeluk Agama Islam. Jakarta: Al Azhar, $200 \mathrm{I}$.

Rasjid dan Sulaiman, Figh Islam. Jakarta: Attahiriyah, 1976.

Saltut dan Mahmud: Akidah dan Syariah. Jakarta, Bina Aksara, 1985.

Sodiq, Peranan Yayasan Ar-risalah. Bandung: Yayasan Arrisalah, 1996.

Sukandarrumidi, Metodologi Penelitian, Petunjuk Praktis untuk Peneliti Pemula. Yogyakarta: Gadjah Mada University Press, 2004.

Syarifuddin Amir, Garis-garis Besar Fiqh. Jakarta: Kencana, 2003.

Tim Penyusun Kamus Pusat Bahasa. 2002. Kamus Besar Bahasa Indonesia. Cet. Kedua. Edisi III. Jakarta: Balai Pustaka.

Tim Penyusun Kamus Pusat Bahasa. 2007. Kamus Besar Bahasa Indonesia. Cet. Keempat. Edisi III. Jakarta: Balai Pustaka. 